\title{
Reduction in the incidence of myocardial infarction with sodium-glucose linked cotransporter-2 inhibitors: evident and plausible
}

Richard E. Gilbert ${ }^{1 *}$ (1) and Kim A. Connelly ${ }^{2}$

Keywords: Sodium-glucose linked cotransporter-2, Myocardial infarction, Cardiovascular outcome trials, Stroke

Coincident with the recent reporting of the Dapagliflozin Effect on Cardiovascular Events (DECLARE) trial in the New England Journal of Medicine [1], the Lancet published a systematic review and meta-analysis of cardiovascular outcome trials for the three widely marketed SGLT2 inhibitors: canagliflozin, empagliflozin and dapagliflozin [2].

While able to reduce hospitalization for heart failure, kidney disease progression and cardiovascular death, sodium-glucose linked cotransporter-2 (SGLT2) inhibitors are not generally regarded as agents that reduce the atherosclerotic components of MACE: myocardial infarction and stroke. The meta-analysis of the SGLT2 inhibitor cardiovascular outcome trials suggests, however, that for this drug class myocardial infarction and stroke should be viewed separately [2]. Not only was the reduction in myocardial infarction statistically significant 0.89 (95\% confidence intervals: $0.80,0.98$ ) but the point estimates for all three trials also lay on the favourable side of unity. These findings contrast those for stroke and amputation where the hazard ratios were non-significant and where heterogeneity in the direction of effect was also evident (Fig. 1).

The observed difference in hazard ratios among myocardial infarction, stroke and amputation suggest that a primary anti-atherosclerotic effect of the SGLT2 inhibitors is unlikely since such an effect would have been expected to reduce myocardial infarction and stroke similarly, as is the case with cholesterol lowering [3] and

\footnotetext{
*Correspondence: richard.gilbert@utoronto.ca

${ }^{1}$ Division of Endocrinology, St. Michael's Hospital, 30 Bond Street, Toronto, ON M5B 1W8, Canada

Full list of author information is available at the end of the article
}

antihypertensive therapy [4]. And though it is possible that the reduction in myocardial infarction is a chance finding, the adjudication of events, the robust numbers and the statistical testing all suggest that this is not the case. Accordingly, these data from randomized controlled trials with the support of similar findings in the so-called real world setting [5] should be regarded as hypothesis-generating.

Infarction occurs when the demands of the myocardium exceed the supply of $\mathrm{O}_{2}$ needed to maintain viability. As such, its likelihood can be reduced by either augmenting $\mathrm{O}_{2}$ supply or reducing its demand. Nitrates, for instance, are thought to improve symptoms in patients with flow-limiting coronary artery disease primarily by reducing preload that, in turn, leads to a diminution in left ventricular volume, wall tension and $\mathrm{O}_{2}$ demand [6]. Nicorandil, for instance, a nitrate derivative with venodilating properties, reduces preload and the risk of myocardial infarction following percutaneous coronary intervention [7]. Through the promotion of an osmotic diuresis, SGLT2 inhibitors also reduce preload and while detailed human studies are in progress, animal studies have demonstrated the ability of this class of agent to similarly reduce left ventricular volumes in systole and diastole and thereby wall tension [8]. Accordingly, we hypothesize that the diminution in myocardial infarction with SGLT2 inhibitors is a consequence of preload reduction in patients with established cardiovascular disease. This drug class would therefore not be expected influence the risk of stroke or critical limb ischemia or be particularly effective in patients with multiple risk factors alone.

In conclusion, we view the meta-analysis-based finding of a statistically significant reduction in myocardial 


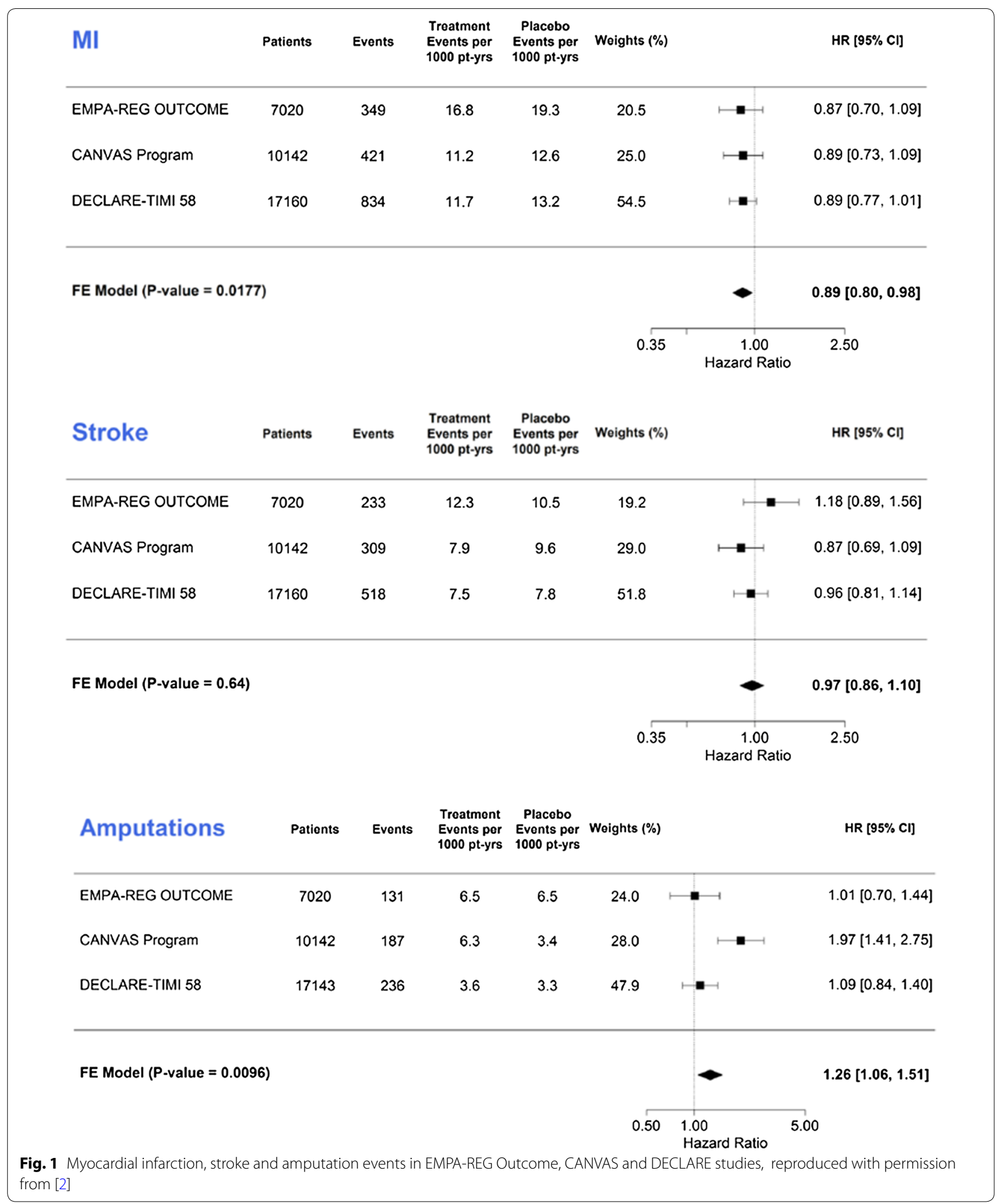


infarction risk in diabetic individuals treated with SGLT2 inhibitors as real, and consistent with the known effects of this drug class on cardiac preload.

\section{Abbreviations}

SGLT2: sodium-glucose linked cotransporter-2; CANVAS: Canagliflozin Cardiovascular Assessment Study; DECLARE: Dapagliflozin Effect on Cardiovascular Events; MACE: major adverse cardiovascular events.

\section{Authors' contributions}

Both authors conceived the idea related to this commentary and co-wrote the manuscript. Both authors read and approved the final manuscript.

\section{Author details}

${ }^{1}$ Division of Endocrinology, St. Michael's Hospital, 30 Bond Street, Toronto, ON M5B 1W8, Canada. ${ }^{2}$ Division of Cardiology, St. Michael's Hospital, 30 Bond Street, Toronto, ON M5B 1W8, Canada.

\section{Acknowledgements}

Dr. Gilbert is the Canada Research Chair in Diabetes Complications and this work was supported in part by the Canada Research Chairs'Program. Dr. Connelly is supported by a new investigator reward from the CIHR and an early researcher award from the Ministry of Ontario.

\section{Competing interests}

Dr. Connelly has received research grants from Astra Zeneca and Boehringer Ingelheim; has received travel support from Boehringer Ingelheim; and has received honoraria for speaking engagements and ad hoc participation in advisory boards from Astra Zeneca, Boehringer Ingelheim, Sevier, Merck, Novo Nordisk, and Janssen.

Dr. Gilbert has received research grants from Astra Zeneca and Boehringer Ingelheim; travel support from AstraZeneca; and honoraria for speaking engagements and ad hoc participation in advisory boards from Astra Zeneca, Boehringer Ingelheim, and Janssen. He is also a shareholder in the biotechnology companies Certa, OccuRx and Fibrocor.

\section{Availability of data and materials}

All data is available publically and has been cited.

\section{Consent for publication}

The authors consent for publication.

\section{Ethics approval and consent to participate}

Not applicable.
Funding

Not applicable.

\section{Publisher's Note}

Springer Nature remains neutral with regard to jurisdictional claims in published maps and institutional affiliations.

Received: 18 December 2018 Accepted: 4 January 2019

Published online: 11 January 2019

\section{References}

1. Wiviott SD, Raz I, Bonaca MP, Mosenzon O, Kato ET, Cahn A, Silverman MG, Zelniker TA, Kuder JF, Murphy SA, et al. Dapagliflozin and cardiovascular outcomes in type 2 diabetes. N Engl J Med. 2018. https://doi. org/10.1056/NEJMoa1812389.

2. Zelniker TA, Wiviott SD, Raz I, Im K, Goodrich EL, Bonaca MP, Mosenzon O, Kato ET, Cahn A, Furtado RHM, et al. SGLT2 inhibitors for primary and secondary prevention of cardiovascular and renal outcomes in type 2 diabetes: a systematic review and meta-analysis of cardiovascular outcome trials. Lancet. 2019:393(10166):31-9.

3. Bohula EA, Wiviott SD, Giugliano RP, Blazing MA, Park JG, Murphy SA, White JA, Mach F, Van de Werf F, Dalby AJ, et al. Prevention of stroke with the addition of ezetimibe to statin therapy in patients with acute coronary syndrome in IMPROVE-IT (Improved Reduction of Outcomes: Vytorin Efficacy International Trial). Circulation. 2017;136(25):2440-50.

4. Cushman WC, Evans GW, Byington RP, Goff DC Jr, Grimm RH Jr, Cutler JA, Simons-Morton DG, Basile JN, Corson MA, Probstfield JL, et al. Effects of intensive blood-pressure control in type 2 diabetes mellitus. N Engl J Med. 2010:362(17):1575-85.

5. Kosiborod M, Lam CSP, Kohsaka S, Kim DJ, Karasik A, Shaw J, Tangri N, Goh SY, Thuresson $\mathrm{M}$, Chen $\mathrm{H}$, et al. Cardiovascular events associated with SGLT-2 inhibitors versus other glucose-lowering drugs: the CVD-REAL 2 study. J Am Coll Cardiol. 2018;71(23):2628-39.

6. Divakaran S, Loscalzo J. The role of nitroglycerin and other nitrogen oxides in cardiovascular therapeutics. J Am Coll Cardiol. 2017:70(19):2393-410.

7. Li Y, Liu H, Peng W, Song Z. Nicorandil improves clinical outcomes in patients with stable angina pectoris requiring $\mathrm{PCl}$ : a systematic review and meta-analysis of 14 randomized trials. Expert Rev Clin Pharmacol. 2018;11(9):855-65.

8. Connelly KA, Zhang Y, Visram A, Advani A, Batchu S, Desjardins J, Thai K, Gilbert RE. Empagliflozin improves diastolic function in a non-diabetic rodent model of heart failure with preserved ejection fraction. JACC Basic Transl Sci. 2019 (In Press)
Ready to submit your research? Choose BMC and benefit from:

- fast, convenient online submission

- thorough peer review by experienced researchers in your field

- rapid publication on acceptance

- support for research data, including large and complex data types

- gold Open Access which fosters wider collaboration and increased citations

- maximum visibility for your research: over $100 \mathrm{M}$ website views per year

At $\mathrm{BMC}$, research is always in progress.

Learn more biomedcentral.com/submissions 